\title{
O CUIDAR DO CUIDADO: O CUIDADO COMO ÉTICA E O PAPEL DOS EDUCADORES
}

\author{
Loani Cristina Buzo Pontes ${ }^{1}$
}

\section{Introdução}

Iniciar um movimento de pensamento a partir da expressão "o cuidar do cuidado" e logo em seguida inseri-lo numa perspectiva ética situando-o a partir dos estudos de Foucault em seu curso no College de France (1981-1982) acerca deste conceito, nunca foi tarefa fácil. Torna-se então, ainda mais desafiador, quando problematizado em torno da discussão desse cuidado e a relação dos bebês com os educadores de creche, onde inevitavelmente situa-o em um campo em que as tensões históricas, políticas e sociais são consideradas territórios de disputas dentro do contexto das políticas públicas de educação.

Pensada a partir da expressão "souci de soi", traduz o grego "epimeléia heautô̂" (em latim, "cura sui"); cuidado de si mesmo parece a melhor tradução para o português. No mundo greco-romano, foi o modo pelo qual a liberdade individual ou a liberdade cívica se reflete como ética (CASTRO, 2016, p. 96).

Essa temática marcou o último movimento de pensamento sob o qual Foucault se dedicou no final da sua vida. A hermenêutica do sujeito (1981-1982) e O Governo de Si e dos Outros (1982-1983), passando pelo que Foucault denomina a época do cuidado de si mesmo, da qual se ocupa de maneira intensa, trazendo a inquietude do ser. Esse movimento de pensamento, não segue a ordem linear, cronológica, histórica, mas a da "problematização foucaultiana - com idas e vindas - das relações entre governo, liberdade e verdade." (CASTRO, 2015, p. 121); ou como escreve Brandão (2015, p. 284): "O cuidado de si é uma atividade que implica não somente conhecimento, mas, também técnica, colocando em jogo as formas de exterioridade, o corpo, toda essa superfície do eu. Em outras palavras, as experiências".

Os estudos de Foucault (1981-1982) no curso do Collège de France acerca do cuidado de si na perspectiva da cultura greco-romana emergem como possibilidade de diálogo dentro dessa interlocução a qual propõem-se ao leitor, no sentido de apontar o cuidado e a relação com os bebês para além da internalização de técnicas, normas e procedimentos, mas como um movimento anterior e/ou simultâneo, como um movimento de interrogar-se sobre si, de olhar para os efeitos da sua atuação numa perspectiva ética, para assim empreender uma nova atitude nesse cuidado para com o outro, compreendendo o cuidado como ética, forma de ser, estar, agir e de vivere de ensinar, perpassando as experiências.

Nesse movimento e como forma de dar luz a vivência do cuidado como ética nessa perspectiva trazemos à discussão esse cuidado ético e a incitação a liberdade na relação entre bebês e os educadores da creche. Sua atuação tem sido mediado pelo cuidado com o outro? Os profissionais que atuam em creches detém enquanto processo reflexivo, o cuidado como movimento de ser e de principalmente atuar com os bebês, uma vez que são responsáveis por tornar o outro melhor?

Mais adiante aprofundaremos as reflexões em torno desse movimento de pensamento e do diálogo que ela mobiliza com o conceito de Foucault (1982) no cuidado de si.

Todavia, a mobilização destes conceitos somados a vivência diária dos bebês em creche incita a uma nova tensão, entre o modo como são organizadas as políticas públicas de

\footnotetext{
${ }^{1}$ Mestranda em Educação (FE-Unicamp). Especialista em Gestão Pública (Unicsul, 2016). Diretora da EMEB Hilda Maria Alves Paschoalotto - Jundiaí-SP. E-mail: 1179204@g.unicamp.br.
} 
atendimento aos bebês em creche e os profissionais que atuam nesse cuidado, questionando a própria instituição em torno das práticas de cuidado de si como possibilidade de liberdade.

\section{O cuidado de si e o papel dos educadores da creche}

Nos anos 80, Michel Foucault dedicou-se a analisar as relações entre sujeito e verdade (buscando compreender como se vincula uma verdade ao sujeito), principalmente preocupandose com o cuidado de si desde a antiguidade, como atitude de estranhamento permanente de si mesmo, das verdades, das amarras do poder, numa busca pela liberdade numa perspectiva ética.

Foucault (2010) afirma que as relações de poder têm uma extensão considerável nas relações humanas, no seio da família, nas relações pedagógicas, no corpo político, mas caracterizam-se por sua mobilidade e pela responsabilidade de práticas de liberdade (o que é diferente da liberação absoluta). Quando há fixidez, irreversibilidade, imobilidade, trata-se de estados de dominação, opressão, onde os movimentos de resistência e práticas de liberdade não existem. Foucault diz que no seio das relações de poder (e não de modo exterior a elas) há práticas refletidas de liberdade, ou seja, há a possibilidade da ética. Para ele "...a liberdade é a condição ontológica da ética; mas, a ética é a forma refletida assumida pela liberdade" (Foucault, 2010). Segue seu movimento de pensamento trazendo a discussão que o cuidado de si se constituiu no mundo greco-romano como modo pelo qual a liberdade individual foi pensada como ética.

Ao tentar situar e focalizar o cerne das preocupações acerca das relações entre sujeito e verdade, sujeito e conhecimento, utilizou-se da máxima "conhece-te a si mesmo" (na expressão grega gnôthiseautón). Entretanto opta em utilizar a noção grega de "cuidado de si mesmo" (epiméleia heauntô̂) para estudar essas relações, uma vez que "conhece-te a si mesmo" era proferido para evidenciar a necessidade de prudência, onde o homem em sua mortalidade deveria cuidar para não afrontar a verdade das divindades. Já no contexto de "cuidado de si" relaciona como forma de uma atenção a si mesmo, algo que requer maior cuidado e atenção. (FOUCAULT, 2010):"quando surge este preceito délfico (gnôthi seautón), ele está, algumas vezes e de maneira muito significativa acoplado, atrelado ao princípio do cuida de ti mesmo"; ou seja:"Mais como uma espécie de subordinação relativamente ao preceito do cuidado de si que se formula a regra conhece-te a ti mesmo".

De acordo com Foucault, no texto "Apologia a Sócrates", de Platão, a função de Sócratesé incitar os outros a ocuparem-se consigo mesmos, a terem cuidado consigo. Sócratesé aquele que desperta para o cuidado, onde esse cuidado de si passa a ser considerado como o momento primeiro do despertar. Nas palavras de Foucault (2010): “O cuidado de si é uma espécie de aguilhão que deve ser implantado na carne dos homens, cravado na sua existência, e constitui um princípio de agitação, um princípio de movimento, de permanente inquietude no curso da existência".

Seu propósito era incitar a cada um o cuidado de si mesmo, no sentido de inquietar-se nesse movimento, sem que isso se tornasse um movimento egoísta e individual, mas sim com o objetivo de questionar-se e de assumir uma nova ação.

Sócrates - Como assim Alcibíades? Não reconheces que cuidar de alguma coisa é fazer algo a seu respeito?

Alcibíades - Decerto.

Sócrates - E sempre que o tratamento deixar essa coisa melhor do que era antes, nao dizes que ela foi bem cuidada?" (PLATÃO, 1975, p. 236)

Nesse diálogo Sócrates, que se afirmava como um instrumento dos deuses com papel de incitar as pessoas ao cuidado de si, diz a Alcibíades que cuidar é acima de tudo um "fazer algo a respeito", tornando-o melhor. E que esse fazer nada diz respeito as materialidades, mas 
localiza-se no campo da subjetividade. Portanto, o cuidado de si, está no "entre" ocuparmos com coisas que, mesmo próximas e que nos dizem respeito, não são nós mesmos.

Nessa perspectiva do cuidado de si como ética é que tomamos o movimento de pensamento foucaultiano para pensar o papel do educador na creche, focalizando-o na relação com os bebês.

O primeiro ponto a ser levantado em relação ao conceito de cuidado de si e os bebês, refere-se ao momento de vida sob o qual o bebê está para ser cuidado. Sob a atenção ou não daqueles que o cercam. Uma relação de poder já estabelecida seja no seio familiar ou de políticas públicas de atendimento a bebês, no caso a creche, perspectiva sob a qual desenvolvemos essa ideia.

Esse momento pode ser comparado ao que Foucault (2010, p. 115) nos traz:“Antes disso porém, gostaria de colocar um problema prévio que é a questão do Outro ou de outrem, questão da relação com o outro, entendendo-o como mediador entre essa forma da salvação e o conteúdo que se lhe dá de fornecer". Sendo assim: "O outro ou outrem é indispensável na prática de si a fim de que a forma que define essa prática atinja efetivamente seu objeto, isto é, o eu, e seja por ele efetivamente preenchida. Para que a prática de si alcance o eu por ela visado, o outro é indispensável" (2010, p. 115).

Nesse sentido, temos como indispensável a relação com o outro para a constituição do sujeito bebê, uma vez que cuidar de si, perpassa todo o cuidado recebido pelo outro dentro desse movimento entre mediado, que no caso, trazemos o bebê e o mediador, enquanto o educador de creche. Refletir sobre essa ação enquanto processo de busca pela salvação, torno o outro melhor, ou seja, uma atitude de cuidado ético enquanto ação e busca pela liberdade.

Algumas questões se levantam diante dessa discussão a qual perpassa a obra de Foucault, e sob a ideias que desenvolvemos aqui a partir do cuidado como ética, dentre elas: o educador de creche está atento para esse cuidado de si, que vai além daqueles relacionados a higiene, mas como uma ação contínua de atenção a si mesmo, reflexão sobre suas emoções, sobre a relação que estabelece com o outro (no nosso caso os bebês), sobre as intervenções que faz, num sentido mais pleno de busca de liberdade e da construção de um ética enquanto possibilidade de fugir a reprodução social das desigualdades já postas sobre os bebês que frequentam a creche? Será que estão atentos em relação a escuta, olham plenamente para os bebês a partir da sua potência, da imanência do ser? São incitadores do desenvolvimento pleno ou apenas reprodutores de normas? Cuidam de si ao cuidar do outro?

Pensar nessa posição que o educador ocupa na relação diária com os bebês envolve acima de tudo uma tomada de posição, como resposta e ressonâncias concectadas a este coletivo. Nesse posicionamento do educador em relação aos bebês, implica acima de tudo numa atitude ética, num cuidado de si a partir de uma reflexão sobre seus modos de ação, como forma de ser e de consequentemente de cuidar. Isso envolve não só intervir diretamente na ação dos bebês, ou só apenas observá-los, requer dar sustentação ás suas experiências e vivências dentro desse espaço.

A partir desse movimento de pensamento, cabe levar a fio a discussão de como as políticas públicas de formação inicial e continuada tem focalizado a necessidade de inserir no ambiente da creche educadores conscientes de si e de seu papel formador no cuidado com o outro.

É fundamental questionar como que esses profissionais estão sendo cuidados em nossas creches, se estamos cuidando desse cuidar pensando na formação do sujeito, no movimento de levalo ao conhecimento de si, para devolve-lo as práticas diárias como aquele que se transforma nessa relação de cuidado, capazes de sustentar as singularidades e possibilidade de liberdade dos bebês.

Posiciona-lo nessa discussão como desafio em busca de educadores que reconheçam seu papel e que sejam incitadores de um cuidado ético, como ferramenta de fuga ao padrão e aos estigmas históricos, políticos e sociais impostos sobre a creche e sobre os bebês que nela são cuidados. 


\section{Considerações finais}

Esse breve artigo ao qual propus iniciar uma interlocução com o leitor e desse modo questionar o cuidado e o papel do educador dentro das creches nas relações diretas e diárias com os bebês, emerge um campo de discussão para além daqueles relacionados com a formação do sujeitos, mas chama para si uma discussão histórica, política e social.

Nesse campo em disputa temos a visão clara da influência da formação do sujeito no cuidado de si e consequentemente no cuidado do outro, como carga, legado a se reproduzir. Mesmo que essa discussão ocorra dentro do locus educacional, onde por mais esforço que se faça o cuidado sempre será colocado como atividade "desprofissionalizada", mão de obra barata e questionável, apenas como garantia dos cuidados básicos de higiene e alimentação, pois a esse fim que ela serve e é essa imagem social deve reproduzir.

Assim, trazer nesse diálogo a compreensão do sujeito em Foucault, dos processos pelos quais se forma, pelos quais conhece o mundo e a si mesmo, focalizando uma das suas últimas obras como A hermenêutica do sujeito (2010), que reflete a sua busca pessoal de conhecer a si para pensar os modos de agir, que encontra nessa discussão um terreno fértil para se pensar no cuidado de si e do outro e nas construções que se dá nessa relação. Pensar o quanto de mim reflete no outro e o quanto eu preciso olhar e cuidar de mim na busca de uma ética, como modo de vida, cujo o objetivo é a liberdade.

Por fim, configura-se como a experiência de si que reflete no outro. Uma reflexão dos educadores na possibilidade de repensar e reencaminhar a sua ação diária do cuidado. Reconhece-se que o cuidado na creche é ressignificado na medida em que é reconhecido, sobretudo, como um movimento de atentar-se a si mesmo, para que dessa forma se deem conta do caráter disciplinador e modelador que as práticas escolares têm imposto desde muito cedo aos bebês de forma a reencaminhar as formas de fazer e de cuidar do outro.

Considerar a qualidade ética do cuidado, para além do atendimento às necessidades básicas do bebê, implica em questionar o modo de ser e de fazer, questionar a própria instituição e as as políticas públicas que a cercam, questionar acima de tudo nossa capacidade de olhar e agir verdadeiramente com os bebês numa busca de incitação a liberdade.

\section{Referências}

CERISARA, A. B. Professoras de educação infantil: entre o feminino e o profissional. São Paulo: Cortez, 2002

FOUCAULT, M. A hermenêutica do sujeito. São Paulo: Martins Fontes, 2010.

KRAMER, S. Direitos da criança e projeto político-pedagógico de educação infantil, In: BASÍLIO, L. C.; KRAMER, S. Infância, educação e direitos humanos. São Paulo: Cortez, 2003.

MONTENEGRO, T. Educação infantil: a dimensão moral da função de cuidar. Revista Psicologia da Educação, São Paulo, n. 20. p. 77-101, 2005.

PLATÃO. Diálogos. Pará: Universidade Federal do Pará, 1975

TIRIBA, L. Crianças, natureza e educação infantil. Tese de Doutorado. Departamento de Educação: PUC-Rio, 2005. 